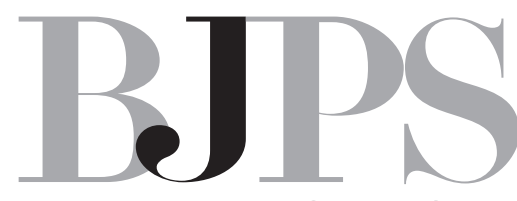

\title{
Celebrating the 70th Anniversary with increased international visibility!
}

Revista Brasileira de Ciências Farmacêuticas (RBCF) is celebrating its 70th Anniversary! Formerly as Anais de Farmácia e Odontologia, it changed the title to Revista da Faculdade de Farmácia e Bioquímica da Universidade de São Paulo and Revista de Farmácia e Bioquímica da Universidade de São Paulo. Those scientific periodicals have faced many challenges, one at a time, mainly of financial support. Thanks to the efforts and the permanent ideal of many professors from the Faculty of Pharmaceutical Sciences, and Librarians from the Chemistry and Pharmaceutical Sciences Libray, members of Publishing Committee, the periodical has continued in its aim of diffusing the Pharmaceutical Sciences that has been produced, especially, in the State of São Paulo. It is mandatory to acknowledge the hard work that had been developed by those people. On behalf of Professor Andrejus Korolkovas, we thank all the members that keep Revista going on publishing the scientific research of those who was devoted to the Pharmaceutical area. It is worth to note that the periodical has never stop publishing but in 1973, due to insufficient funds.

In 1993, the University of Sao Paulo introduced a new policy for supporting its publishing and to have a Scientific Editor was a mandatory requirement. At that time, Professor Korolkovas was indicated by the Dean of the Faculty to this honorable position. In 1996, when he passed the way, he was substituted by Professor Elizabeth Igne Ferreira. Since 1999, RBCF has assumed the present name and from now on will be changed again.

Therefore, we are pleased to introduce Brazilian Journal of Pharmaceutical Sciences (BJPS) to the academic community. It is not only a matter of changing the title. More than this it is a change of concepts as we are adopting English as the official language, facing the challenges that this may bring. English is almost worldwide the language of Science and if we want to accomplish our ideal of internationally diffusing the Pharmaceutical Sciences that are being produced in Brazil we must follow the rules. We must reach the world.

Together with the new title a complete reformulation of the layout was made and an updated system of submitting and reviewing the manuscripts will be implemented soon. Also, Associate Editors, one for each area of Pharmaceutical Sciences, will integrate the new structure of Editorial Board. 
Considering the changes that have been decided in the end of 2008, and taking into account that many manuscripts in Portuguese have already been accepted, this issue, the first of volume 45, will be mixed up: part in Portuguese and part in English. The next will be only in English.

The integration to SciELO in 2004, and the support of funding agencies, as CNPq and FAPESP, and of the Support Program for Periodical and Scientific Publications of the University of São Paulo during the last years, have been essential for the improvement of our journal and to enhance its credibility in academy. Also its high classification in QUALIS, from CAPES Pharmacy Committee, was fundamental for the increased interest we have testified.

The recent inclusion of RBCF, and from now on BJPS, in ISI Web of Knowledge is the best news towards increasing international visibility!

Last, but not least, we are very much grateful to all authors and referees that have been working all over those seven decades of our periodical existence. Also, the Committees and the Secretaries/Executive Editor have displayed decisive work. On behalf of Leila Aranha, whose enthusiasm and hard work have been essential for the Journal's advance we compliment all their members.

Hope we consolidate the value of our journal, now BJPS, in the area of Pharmaceutical Sciences in Brazil and in the world. We need you to join us!

Elizabeth Igne Ferreira

Scientific Editor 